\title{
AN IMPROVED METHODOLOGY FOR MULTI-CRITERIA EVALUATIONS IN THE SHIPPING INDUSTRY
}

\author{
UDC 629.5.01:519.8
}

Original scientific paper

\begin{abstract}
Summary
This paper presents a reliable, easy and more objective approach for ranking and determining preference in a multi-criteria decision-making problem within the shipping industry. Through the integration of the improved score function, fuzzy Shannon's entropy method and the interval-valued intuitionistic fuzzy M-TOPSIS method, for ranking and for representing the aggregated effect of positive and negative evaluations in the performance ratings of the alternatives based on interval-valued intuitionistic fuzzy set (IVIFS) data. The integration of the improved score function, fuzzy Shannon's entropy method and the intervalvalued intuitionistic fuzzy M-TOPSIS method in this paper has provided a whole new approach for solving multi-criteria decision-making problems. The improved score function which is applied to the calculation of the separation measures of each alternative from the positive and negative ideal solutions. Reflect and model the fuzziness and hesitation of the decision-maker subjective assessment, while the fuzzy Shannon's entropy method is been used for calculating the criteria weight. The proposed method has successfully been applied to rank and determined the most appropriate shipping partner for a shipping company located in Malaysia, and for a modified hypothetical example which is based on the selection of a preferred Ship as a reference for a new design. The model has been compared with existing model and we can conclude, it provides a better alternative method for ranking and for the determination of preference in a multi-criteria decision-making problem.
\end{abstract}

\section{Key words: Interval-Valued Intuitionistic Fuzzy M-TOPSIS model, Fuzzy Shannon's Entropy method, Multi-Criteria Decision-Making, Shipping Company}

\section{Introduction}

In multi-criteria decision-making (MCDM) problems, such as in design selection, equipment selection, supplier selection and in the evaluation of business strategic performance, it is necessary to consider many factors/criteria simultaneously before selecting or ranking the alternatives. The Decision-Makers (DMs), desirable alternative(s) are chosen by providing preference information in the form of, exact numerical value, interval value [1] or with linguistic variables [2]. However, such preference information's are often characterized by ambiguity due to vagueness and uncertainty [1], [3]. This ambiguity caused 
by vagueness and uncertainty has remained a big challenge for DMs during the last several years and has resulted in more and more interest in the topic from researchers.

In handling these issues Zadeh, [4], who introduced the concept of fuzzy set theory, has outlined how fuzzy set could be used to characterize complex systems and decision-making processes. This breakthrough resulted in the extension of MCDM techniques in fuzzy environment. One of such extension includes; the fuzzy technique for order preference by similarity to ideal solution (fuzzy-TOPSIS) which was developed by Hwang and Yoon in 1981 [5]. However, due to some of its limitations, many different improvements and modifications have been proposed and applied in recent years, prominently among this improvement include the Modified Technique for Order Preference by Similarity to the Ideal Solution (M-TOPSIS) model by Ren et al., in 2007 [6].

In 1986, Atanassov introduced a new theory, called intuitionistic fuzzy set (IFS) theory [7], and as a follow in 1989, Atanassov introduced the interval-valued intuitionistic fuzzy set (IVIFS) which is based on a comparative analysis of interval-valued fuzzy sets (IVVS) and IFS [8]. Unlike the traditional fuzzy set theory, the IFS and the IVIFS are characterized by a membership function and a non-membership function. According to Saurav et al. [9] the intuitionistic set(s) are more capable than the traditional fuzzy sets at handling vagueness and uncertainty information in practice. While Liu \& Wang, [8], Xu \& Liao, [11] and Xu \& Liao, [12] describes the benefits of IFS theory to includes. (1) It ability to model unknown information using hesitation degree. In a situation where DMs are unsure about the preferences of an assessment, the IFS theory is most suitable to get the opinions of the experts as compared to the fuzzy sets. (2) It represents three grades of membership function which include membership degree, non-membership degree, and hesitancy degree, and (3) all fuzzy numbers in the IFS theory can all be used to represent vagueness of "agreement" but, however, cannot depict the "disagreement" of the Expert. Hence, the IFS can be said to consider opinions from three sides to arrive at the preferred one.

Extensive literature review shows that the application of IFS and the IVIFS in MCDM problems has increased significantly over the past few years, with many research literature published both on the theoretical and practical aspects of its applications [1],[13]-[18]. With researcher like $\mathrm{Li}$ [20] extending the generalized ordered weighted averaging operators to investigate multi-attribute decision-making problems using the score function and the accuracy function for ranking IFS. Ye [21] presented a multi-criteria fuzzy decision-making method using a novel accuracy function for the IVIFS. While Bai [1] presented the improved score functions for ranking IVIFSs and for solving MCDM problems.

In the present study therefore, as a follow-up, the M-TOPSIS model is extended into an intuitionistic fuzzy environment (Interval-Valued Intuitionistic Fuzzy M-TOPSIS) by integrating the intuitionistic algorithm originally given by Bai, [16] into the M-TOPSIS model, while the weight of criteria applied is calculated using the fuzzy Shannon's entropy method which is based on subjective and objective weight factors.

The proposed Interval-Valued Intuitionistic fuzzy M-TOPSIS model has been applied to rank and determined the most appropriate shipping partner for a shipping company located in Selangor-Malaysia, and for a modified hypothetical example which is based on the selection of a preferred Ship as a reference for a new design.

The rest of the paper is organized as follows; Section 2 presents the concept of IFS as it relates to the improved score function of IVIFS and the fuzzy Shannon's entropy weight. The Interval-Valued Intuitionistic Fuzzy M-TOPSIS model is presented in section 3. In section 4, a real case study and a modified hypothetical example originally presented by Ye, [21] is applied to demonstrate the proposed method and to compared the result of the model. Finally in section 5, the conclusion is presented. 


\section{Preliminaries}

In this section, we introduce the fundamental definitions and concepts of IFS theory as well as the improved score function as it relates to the IVIFS.

\section{Definition 1}

Let $\mathrm{D}[0,1]$ be the set of all closed subintervals of the interval $[0,1]$ and let $\mathrm{X}(\neq \varnothing)$ be a given set. An IVIFS $A$ in $X$ is expressed as [16] [21];

$$
A=\left\{\left\langle x, \mu_{A}(x), v_{A}(x)\right\rangle \mid x \in X\right\},
$$

where $\mu_{A}: X \rightarrow \mathrm{D}[0,1], v_{A}: X \rightarrow \mathrm{D}[0,1]$ with the condition $0 \leq \sup \mu_{A}(x)+\sup v_{A}(x) \leq$ $1, \forall x \in X$.

The intervals $\mu_{A}(x)$ and $v_{A}(x)$ denote, respectively, the degree of membership and non-membership of the element $x$ to the set $A$. Thus, for each $x \in X$ the intervals $\mu_{A}(x)$ and $v_{A}(x)$ are closed and their lower and upper end points are denoted by $\mu_{A L}(x), \mu_{A U}(x), v_{A L}(x)$ and $v_{A u}(x)$ respectively. We can denote the set as;

$$
A=\left\{\left\langle x,\left[\mu_{A L}(x), \mu_{A U}(x)\right],\left[v_{A L}(x), v_{A U}(x)\right]\right\rangle \mid x \in X\right\},
$$

where $0 \leq \mu_{A U}(x)+v_{A U}(x) \leq 1, \mu_{A L}(x) \geq 0, v_{A L}(x) \geq 0$

For each element $x$, we can compute the unknown degree (hesitancy degree) of an intuitionistic fuzzy interval of $x \in X$ in $A$ which is defined as follows:

$$
\pi_{A}(x)=1-\mu_{A}(x)-v_{A}(x)=\left[1-\mu_{A L}(x)-\mu_{A U}(x), 1-\mu_{A L}(x)-v_{A L}(x)\right]
$$

However, if $\mu_{A}(x)=\mu_{A L}(x)=\mu_{A U}(x)$ and $v_{A}(x)=v_{A L}(x)=v_{A U}(x)$, then the given IVIFS $A$ is reduced to an ordinary IFS. For convenience, the IVIFS can also be expressed as $A=$ $([a, b],[c, d])$.

In order to make comparisons between two IVIFSs, metric methods have been introduced by several researchers [20][21], however, in this study we will be concern with the improved score function originally proposed by Bai [16], for the ranking, and the representation of the aggregated effect of positive and negative evaluations in the performance ratings of the alternatives based on IVIFS data in the M-TOPSIS model. The computation formula for the improved score function is given as;

$$
I(A)=\frac{a+a(1-a-c)+b+b(1-b-d)}{2}, \text { where } I(A) \in[0,1]
$$

When $a=b$ and $c=d$, the IVIFS will degenerate to the IFS while the improved score function of IVIFS will degenerate to the score function of IFS proposed by Ye, [21].

\subsection{Fuzzy Shannon's entropy}

The Shannon's entropy concept can be referred to as a general measure of uncertainty in the information formation in terms of probability theory [22]. The concept is said to have a dominant role in the information theory [23]. According to Saad et al., [24], Shannon's entropy concept is 'appropriate for calculating the relative contrast intensities of criteria to represent the average intrinsic information transmitted to the decision maker'.

The Shannon's entropy method which was extended by Lotfi \& Fallahnejad,[25] for imprecise data, especially for interval and fuzzy data case, has found application in several fields of studies including, management, engineering, information sciences, agricultural sciences etc. and has prominently been used in the determination of criteria weight. The implementation steps are explained below; 
In computing criteria weight using the fuzzy Shannon's entropy weight method in this study, first, a decision matrix is formed for the criteria to express the level of importance of each of the criterion using linguistic variables, and are later converted to the interval-valued intuitionistic fuzzy values and then to crisp value, the procedure are explained in the steps below [24].

Step 1. Normalized each of the criterions to obtain the projection value $\widetilde{P}_{i j}$

Step 2. Compute the entropy values $E p_{j}$;

Step 3. Compute the degree of diversification, $d_{j}$ and finally the criteria weight $w_{j}$

\section{Interval-Valued Intuitionistic Fuzzy M-TOPSIS model}

TOPSIS model which is an abbreviation of Technique for Order Preference by Similarity to the Ideal Solution originally proposed by Hwang and Yoon in 1981 [5] has remained one of the most widely used MCDM methods with so many papers published on its applications and in several different field of study including Accounting [26], Management [27], Agriculture [28], Chemical science [29], Design [30], Business [31], Engineering [32], Health and medicine [33], etc. However, due to some of its limitation, many different improvement and modifications have been proposed and applied, prominently among them is the M-TOPSIS model by Ren et al., in 2007 [6].

The M-TOPSIS method which is based on the concept of the original TOPSIS methodology is presented to meet the need for a better and a simpler approach with special regard to the ranking reversals issue in the traditional TOPSIS model. The M-TOPSIS method creates an understanding of the inherent relationship between the relative closeness $(R)$ value and alternative evaluation. It can be described as the process of calculating the distance between the alternatives and the optimal ideal reference points in the $D^{+} D^{-}$plane by constructing the $R$ value to evaluate the quality of the alternative [6]. The basic idea of the MTOPSIS method is depicted in the Fig 1 below.

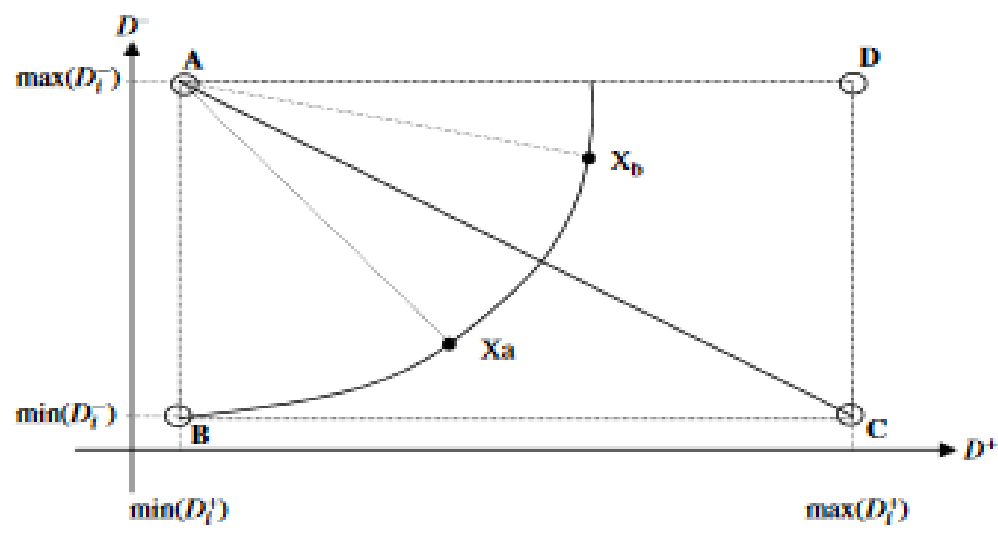

Fig 1. The idea of 'M-TOPSIS' method [6].

The method is unique in its ability to solve ranking reversals issues, that is most common with the traditional TOPSIS methodology and to solve the problem on evaluates failure when alternatives are symmetrical. In the M-TOPSIS, the positive ideal solution and negative ideal solution infinite planes are found and then, the plane is constructed to set the 'optimized ideal reference point'. Finally, the relative distance from each evaluated alternative to the ideal reference point is calculated to determine the ranking order of all alternatives.

In this study, we intend to explore the application of the M-TOPSIS method in an intuitionistic fuzzy environment and to apply the fuzzy Shannon entropy for the determination of the criteria weight using interval-valued intuitionistic fuzzy values. From the best of our 
knowledge, this is the first study to extend the M-TOPSIS method into an intuitionistic fuzzy environment and to apply fuzzy Shannon entropy using interval-valued intuitionistic fuzzy numbers.

The Interval-Valued Intuitionistic Fuzzy M-TOPSIS algorithm can be expressed concisely using the following steps:

Step 1. Construct the interval-valued intuitionistic fuzzy decision matrix ( $\widetilde{D})$ of the alternatives $\left(A_{i}\right)$ with respect to the criteria $\left(C_{i}\right)$, the IVIFS value is expressed as $x_{i j}=$ $\left(\left[a_{i j}, b_{i j}\right],\left[c_{i j}, d_{i j}\right]\right), i=1,2, \ldots, m ; j=1, \ldots, n$.

$$
\begin{gathered}
D_{m x n}\left(x_{i j}\right)= \\
{\left[\begin{array}{cccc}
\left(\left[a_{11}, b_{11}\right],\left[c_{11}, d_{11}\right]\right) & \left(\left[a_{12}, b_{12}\right],\left[c_{12}, d_{12}\right]\right) & \cdots & \left(\left[a_{1 n}, b_{1 n}\right],\left[c_{1 n}, d_{1 n}\right]\right) \\
\left(\left[a_{21}, b_{21}\right],\left[c_{21}, d_{21}\right]\right) & \left(\left[a_{22}, b_{22}\right],\left[c_{22}, d_{22}\right]\right) & \cdots & \left(\left[a_{2 n}, b_{2 n}\right],\left[c_{2 n}, d_{2 n}\right]\right) \\
\vdots & \vdots & \ddots & \vdots \\
\vdots & \vdots & \ddots & \vdots \\
\left(\left[a_{m 1}, b_{m 1}\right],\left[c_{m 1}, d_{m 1}\right]\right) & \left(\left[a_{m 2}, b_{m 2}\right],\left[c_{m 2}, d_{m 2}\right]\right) & \cdots & \left(\left[a_{m n}, b_{m n}\right],\left[c_{m n}, d_{m n}\right]\right)
\end{array}\right]}
\end{gathered}
$$

Step 2. Convert the interval-valued intuitionistic fuzzy decision matrix $D_{m x n}\left(x_{i j}\right)$ to the improved score matrix $R_{m x n}\left(I_{i j}\left(a_{i j}\right)\right)$;

$$
R_{m x n}\left(I_{i j}\left(a_{i j}\right)\right)=\left[\begin{array}{cccc}
I_{11}\left(x_{11}\right) & I_{12}\left(x_{12}\right) & \cdots & I_{1 n}\left(x_{1 n}\right) \\
I_{22}\left(x_{22}\right) & I_{22}\left(x_{22}\right) & \cdots & I_{2 n}\left(x_{2 n}\right) \\
\vdots & \vdots & \ddots & \vdots \\
\vdots & \vdots & \ddots & \vdots \\
I_{m 1}\left(x_{m 1}\right) & I_{m 2}\left(x_{m 2}\right) & \cdots & I_{m n}\left(x_{m n}\right)
\end{array}\right]
$$

Step 3. Determine the weight of each of the evaluating criteria $w_{j}$ using the fuzzy Shannon entropy method. This achieved by first collecting data for the relative importance of the criteria from the assigned DMs and latter for the alternative with respect to the criteria using the linguistic terms as shown in the Table 1 below.

Table 1. Fuzzy numbers for approximating the linguistic variable

\begin{tabular}{|c|c|}
\hline Linguistic terms & $\begin{array}{c}\text { Interval-valued intuitionistic } \\
\text { fuzzy number }\end{array}$ \\
\hline Very low (VL) & $([0.1,0.3],[0.25,0.4])$ \\
\hline Low (L) & $([0.2,0.55],[0.3,0.55])$ \\
\hline Good (G) & $([0.3,0.6],[0.45,0.65])$ \\
\hline High (H) & $([0.5,0.7],[0.6,0.7])$ \\
\hline Excellent (EX) & $([0.6,0.9],[0.75,1.0])$ \\
\hline
\end{tabular}

Step 4. Define the Positive Ideal Solution $\left(A^{+}\right)$and Negative Ideal Solution $\left(A^{-}\right)$for the score function-based matrix,

$$
A^{+}=([1,1],[0,0]), \quad A^{-}=([1,1],[0,0]), \quad j=1, \ldots, n
$$


Step 5. Compute the score function-based separation measures $\left(d^{+}{ }_{i}\left(A^{+}, A_{i}\right)\right.$ and $\left(d^{-}{ }_{i}\left(A^{-}, A_{i}\right)\right.$ of each alternative from the positive ideal and negative ideal solutions using the equation below [16].

$$
d^{+}{ }_{i}\left(A^{+}, A_{i}\right)=\sqrt{\sum_{i=1}^{n}\left[w_{j}\left(1-\left(I_{i j}\left(x_{i j}\right)\right)\right]^{2}\right.}
$$

Similarly,

$$
d^{-}{ }_{i}\left(A^{-}, A_{i}\right)=\sqrt{\sum_{i=1}^{n}\left[w_{j}\left(I_{i j}\left(x_{i j}\right)\right)\right]^{2}}
$$

Step 6. Set a point, say $A$ as the optimized ideal references point $\left(d_{i}\left(A, A_{i}\right)\right.$, for the alternatives that is; $A\left(\min d\left(A^{+}, A_{i}\right), \max d\left(A^{-}, A_{i}\right)\right.$ ) (See Fig 1$)$, Then calculate the distances from each alternative. According to Ren et al.[6], the relative closeness $R_{i}$ to the ideal solution is calculated using the equation.

$$
R_{i}=\sqrt{\left[\left(d\left(A^{+}, A_{i}\right),-\min d\left(A^{+}, A_{i}\right)\right)^{2}+\left(d\left(A^{-}, A_{i}\right),-\max d\left(A^{-}, A_{i}\right)^{2}\right]\right.}
$$

where $i=1,2, \ldots, n$

Step 7. The ranking of alternative $R_{i}$ should be in the increasing order. However if there are two alternatives say $A_{l}$ and $A_{2}$, with $R_{1}=R_{2}$ where $1 \neq 2$, then $R_{i}$ is calculated using $R_{i}=\left(d\left(A^{+}, A_{i}\right),-\min d\left(A^{+}, A_{i}\right)\right)$ where the alternative with the smaller $R_{i}$ value is chosen $[6]$.

\section{Application of the Interval-Valued Intuitionistic Fuzzy M-TOPSIS}

\subsection{Problem formulation}

In this section, we demonstrate the computational process of the Interval-Valued Intuitionistic Fuzzy M-TOPSIS algorithm proposed herein, by using a real case study for case 1 and a hypothetical example for case 2, this is mainly to compare the effectiveness of the model.

Case 1. A shipping company located in Selangor-Malaysia needed to choose a partner to enlarge her business. Four candidates $\mathrm{A}_{1}, \mathrm{~A}_{2}, \mathrm{~A}_{3}$, and $\mathrm{A}_{4}$ were chosen after a preliminary screening for further evaluation. A committee of three experts in the company, i.e. E1, E2, and E3 were formed to determine the most appropriate partner. In the present case, twelve (12) criteria were chosen for the evaluation i.e. ; wider and deeper geographical scope $\left(\mathrm{C}_{1}\right)$, service channels or places $\left(\mathrm{C}_{2}\right)$, increase in frequency of service $\left(\mathrm{C}_{3}\right)$, ships fitting with the cooperative routes $\left(\mathrm{C}_{4}\right)$, using dedicated terminals together $\left(\mathrm{C}_{5}\right)$, extending interests in the integrated hinterland transport service $\left(\mathrm{C}_{6}\right)$, return on stockholders' equity $\left(\mathrm{C}_{7}\right)$, return on assets $\left(\mathrm{C}_{8}\right)$, return on investment $\left(\mathrm{C}_{9}\right)$, the amount of handling equipment $\left(\mathrm{C}_{10}\right)$, terminal hectares $\left(\mathrm{C}_{11}\right)$, and information sharing system $\left(\mathrm{C}_{12}\right)$.

The implementation of the proposed Interval-Valued Intuitionistic Fuzzy M-TOPSIS model is summarized as follows, using the assessment reports from the three (3).

Construct the interval-valued intuitionistic fuzzy decision matrix; the study uses the linguistic variables in Table 1 and then the interval values to express the ratings of the five candidates $A_{i}$ with respect to each of the twelve criteria $C_{j}$ to form the interval-valued intuitionistic fuzzy decision matrix $D_{m x n}\left(x_{i j}\right)$ as shown in Table $2 \& 3$. 
Table 2. Experts ratings with Linguistic terms

\begin{tabular}{|c|c|c|c|c|c|c|c|c|c|c|c|c|}
\hline $\mathrm{C}_{\mathrm{i}}$ & E1 & E2 & E3 & E1 & E2 & E3 & E1 & E2 & E3 & E1 & E2 & E3 \\
\hline & \multicolumn{3}{|c|}{$\mathrm{A}_{1}$} & \multicolumn{3}{|c|}{$\mathrm{A}_{2}$} & \multicolumn{3}{|c|}{$\mathrm{A}_{3}$} & \multicolumn{3}{|c|}{$\mathrm{A}_{4}$} \\
\hline $\mathrm{C} 1$ & L & G & VL & $\mathrm{H}$ & L & $\mathrm{H}$ & VL & $\mathrm{H}$ & G & G & L & VL \\
\hline $\mathrm{C}_{2}$ & $\mathrm{H}$ & $\mathrm{H}$ & $\mathrm{VL}$ & EX & $\mathrm{L}$ & EX & $\mathrm{L}$ & EX & $\mathrm{H}$ & VL & $\mathrm{G}$ & $\mathrm{L}$ \\
\hline $\mathrm{C}_{3}$ & EX & EX & L & VL & $\mathrm{H}$ & $\mathrm{H}$ & G & $\mathrm{H}$ & EX & L & $\mathrm{H}$ & G \\
\hline $\mathrm{C}_{4}$ & $\mathrm{H}$ & $\mathrm{H}$ & G & L & G & G & $\mathrm{L}$ & $\mathrm{L}$ & VL & $\mathrm{G}$ & L & VL \\
\hline $\mathrm{C}_{5}$ & $\mathrm{H}$ & $\mathrm{G}$ & L & G & $\mathrm{H}$ & $\mathrm{G}$ & $\mathrm{H}$ & $\mathrm{G}$ & L & L & $\mathrm{G}$ & $\mathrm{L}$ \\
\hline $\mathrm{C}_{6}$ & $\mathrm{VL}$ & $\mathrm{G}$ & $\mathrm{H}$ & $\mathrm{H}$ & EX & $\mathrm{H}$ & EX & $\mathrm{L}$ & VL & G & $\mathrm{H}$ & G \\
\hline $\mathrm{C}_{7}$ & $\mathrm{~L}$ & $\mathrm{H}$ & VL & EX & $\mathrm{H}$ & $\mathrm{H}$ & $\mathrm{L}$ & $\mathrm{L}$ & $\mathrm{L}$ & $\mathrm{H}$ & $\mathrm{G}$ & $\mathrm{H}$ \\
\hline $\mathrm{C}_{8}$ & $\mathrm{H}$ & EX & L & VL & EX & EX & G & $\mathrm{H}$ & $\mathrm{G}$ & $\mathrm{G}$ & $\mathrm{H}$ & $\mathrm{L}$ \\
\hline $\mathrm{C}_{9}$ & VL & $\mathrm{H}$ & $\mathrm{H}$ & VL & $\mathrm{H}$ & $\mathrm{H}$ & VL & G & VL & $\mathrm{G}$ & $\mathrm{VL}$ & G \\
\hline $\mathrm{C}_{10}$ & $\mathrm{~L}$ & $\mathrm{VL}$ & EX & $\mathrm{L}$ & EX & EX & $\mathrm{L}$ & $\mathrm{L}$ & $\mathrm{L}$ & $\mathrm{H}$ & $\mathrm{L}$ & $\mathrm{H}$ \\
\hline $\mathrm{C}_{11}$ & $\mathrm{G}$ & $\mathrm{L}$ & $\mathrm{H}$ & VL & $\mathrm{H}$ & $\mathrm{H}$ & G & G & $\mathrm{G}$ & EX & $\mathrm{G}$ & $\mathrm{H}$ \\
\hline $\mathrm{C}_{12}$ & VL & $\mathrm{H}$ & G & $\mathrm{H}$ & $\mathrm{H}$ & $\mathrm{G}$ & $\mathrm{L}$ & $\mathrm{H}$ & $\mathrm{H}$ & $\mathrm{L}$ & EX & $\mathrm{G}$ \\
\hline
\end{tabular}

Table 3. Decision matrix for the proposed fuzzy model

\begin{tabular}{|l|c|c|c|c|}
\hline & $\mathrm{A}_{1}$ & $\mathrm{~A}_{2}$ & $\mathrm{~A}_{3}$ & $\mathrm{~A}_{4}$ \\
\hline $\mathrm{C}_{1}$ & $([0.20,0.48]$, & $([0.40,0.65]$, & $([0.30,0.53]$, & $([0.20,0.48]$, \\
& $[0.33,0.53])$ & $[0.50,0.65])$ & $[0.43,0.58])$ & $[0.33,0.53])$ \\
\hline $\mathrm{C}_{2}$ & $([0.37,0.57]$, & $([0.47,0.80]$, & $([0.43,0.72]$, & $([0.20,0.48]$, \\
& $[0.48,0.6])$ & $[0.65,0.88])$ & $[0.55,0.70])$ & $[0.33,0.53])$ \\
\hline $\mathrm{C}_{3}$ & $([0.43,0.67]$, & $([0.27,0.58]$, & $([0.17,0.47]$. & $([0.20,0.48]$, \\
& $[0.55,0.85])$ & $[0.4,0.60])$ & $[0.28,0.75])$ & $[0.33,0.63])$ \\
\hline $\mathrm{C}_{4}$ & $([0.33,0.62]$, & $([0.37,0.63]$, & $([0.33,0.62]$, & $([0.23,0.57]$, \\
& $[0.45,0.68])$ & $[0.50,0.62])$ & $[0.45,0.78])$ & $[0.35,0.53])$ \\
\hline $\mathrm{C}_{5}$ & $([0.30,0.53]$, & $([0.53,0.77]$, & $([0.30,0.58]$, & $([0.37,0.63]$, \\
& $[0.43,0.63])$ & $[0.65,0.68])$ & $[0.43,0.50])$ & $[0.50,0.58])$ \\
\hline $\mathrm{C}_{6}$ & $([0.27,0.52]$, & $([0.53,0.77]$, & $([0.23,0.57]$, & $([0.43,0.67]$, \\
& $[0.38,0.58])$ & $[0.65,0.90])$ & $[0.63,0.35])$ & $[0.55,0.67])$ \\
\hline $\mathrm{C}_{7}$ & $([0.43,0.72]$, & $([0.43,0.70]$, & $([0.37,0.63]$, & $([0.33,0.62]$, \\
& $[0.55,0.55])$ & $[0.58,0.65])$ & $[0.58,0.50])$ & $[0.45,0.67])$ \\
\hline $\mathrm{C}_{8}$ & $([0.37,0.57]$, & $([0.37,0.57]$, & $([0.17,0.40]$, & $([0.23,0.50]$, \\
& {$[0.48,0.78)$} & $[0.48,0.88])$ & $[0.32,0.67])$ & $[0.38,0.63])$ \\
\hline $\mathrm{C}_{9}$ & $([0.30,0.58]$, & $([0.47,0.78]$, & $([0.20,0.55]$, & $([0.40,0.65]$, \\
& $[0.43,0.6])$ & $[0.60,0.60])$ & $[0.30,0.48])$ & $[0.50,0.57])$ \\
\hline $\mathrm{C}_{10}$ & $([0.33,0.62]$, & $([0.37,0.57]$, & $([0.30,0.60]$, & $([0.47,0.73]$, \\
& $[0.45,0.65])$ & $[0.48,0.85])$ & $[0.45,0.55])$ & $[0.60,0.65])$ \\
\hline $\mathrm{C}_{11}$ & $(0.30,0.58]$, & $([0.10,0.30]$, & $([0.23,0.43]$, & $([0.43,0.67]$, \\
& $[0.43,0.63])$ & $[0.25,0.60])$ & $[0.37,0.65])$ & $[0.55,0.78])$ \\
\hline $\mathrm{C}_{12}$ & $(0.40,0.65]$, & $([0.27,0.58]$, & $([0.33,0.62]$, & $([0.37,0.68]$, \\
& $[0.50,0.58])$ & $[0.40,0.68])$ & $[0.45,0.60])$ & $[0.50,0.73])$ \\
\hline
\end{tabular}


Using the improved score function (equation (4)) the interval-valued intuitionistic fuzzy decision matrix $D_{m x n}\left(x_{i j}\right)$ is converted to the improved score matrix $R_{m \times n}\left(I_{i j}\left(a_{i j}\right)\right)$ (i.e. equation (11)) as show in the Table 4 , thereafter the weight of the criteria are determined using the fuzzy Shannon entropy method.

Table 4. Improved score matrix

\begin{tabular}{|l|l|l|l|l|l|l|l|l|l|l|l|l|}
\hline & $\mathrm{C}_{1}$ & $\mathrm{C}_{2}$ & $\mathrm{C}_{3}$ & $\mathrm{C}_{4}$ & $\mathrm{C}_{5}$ & $\mathrm{C}_{6}$ & $\mathrm{C}_{7}$ & $\mathrm{C}_{8}$ & $\mathrm{C}_{9}$ & $\mathrm{C}_{10}$ & $\mathrm{C}_{11}$ & $\mathrm{C}_{12}$ \\
\hline $\mathrm{A}_{1}$ & 0.385 & 0.449 & 0.380 & 0.418 & 0.413 & 0.416 & 0.482 & 0.398 & 0.428 & 0.428 & 0.420 & 0.470 \\
\hline $\mathrm{A}_{2}$ & 0.448 & 0.335 & 0.417 & 0.445 & 0.429 & 0.344 & 0.440 & 0.370 & 0.460 & 0.378 & 0.248 & 0.394 \\
\hline $\mathrm{A}_{3}$ & 0.426 & 0.428 & 0.315 & 0.387 & 0.457 & 0.439 & 0.468 & 0.314 & 0.417 & 0.443 & 0.359 & 0.443 \\
\hline $\mathrm{A}_{4}$ & 0.385 & 0.385 & 0.361 & 0.420 & 0.455 & 0.440 & 0.421 & 0.377 & 0.474 & 0.445 & 0.404 & 0.410 \\
\hline
\end{tabular}

Following the implementation procedure for the fuzzy Shannon entropy method in section 2.2, the decision matrix for the criteria is formed using the linguistic variable (see Table 5), which are then converted to interval-valued intuitionistic fuzzy value (see Table 6). After, the computation of the final weight, the results are presented in crisp values are shown in Table 7.

Table 5. Aggregate decision matrix for fuzzy Shannon's Entropy

\begin{tabular}{|c|c|c|c|c|c|c|c|c|c|c|c|c|}
\hline & $\mathrm{C}_{1}$ & $\mathrm{C}_{2}$ & $\mathrm{C}_{3}$ & $\mathrm{C}_{4}$ & $\mathrm{C}_{5}$ & $\mathrm{C}_{6}$ & $\mathrm{C}_{7}$ & $\mathrm{C}_{8}$ & $\mathrm{C}_{9}$ & $\mathrm{C}_{10}$ & $\mathrm{C}_{11}$ & $\mathrm{C}_{12}$ \\
\hline $\mathrm{E} 1$ & $\mathrm{VL}$ & $\mathrm{G}$ & $\mathrm{L}$ & $\mathrm{EX}$ & $\mathrm{G}$ & $\mathrm{H}$ & $\mathrm{L}$ & $\mathrm{G}$ & $\mathrm{EX}$ & $\mathrm{EX}$ & $\mathrm{G}$ & $\mathrm{G}$ \\
\hline $\mathrm{E} 2$ & $\mathrm{H}$ & $\mathrm{VL}$ & $\mathrm{G}$ & $\mathrm{G}$ & $\mathrm{H}$ & $\mathrm{G}$ & $\mathrm{H}$ & $\mathrm{EX}$ & $\mathrm{EX}$ & $\mathrm{L}$ & $\mathrm{H}$ & $\mathrm{VL}$ \\
\hline $\mathrm{E} 3$ & $\mathrm{G}$ & $\mathrm{H}$ & $\mathrm{EX}$ & $\mathrm{G}$ & $\mathrm{VL}$ & $\mathrm{EX}$ & $\mathrm{EX}$ & $\mathrm{L}$ & $\mathrm{L}$ & $\mathrm{H}$ & $\mathrm{L}$ & $\mathrm{EX}$ \\
\hline
\end{tabular}

Table 6. Aggregate interval-valued intuitionistic fuzzy entropy decision matrix

\begin{tabular}{|c|c|c|c|}
\hline & $\mathrm{E} 1$ & $\mathrm{E} 2$ & $\mathrm{E} 3$ \\
\hline $\mathrm{C}_{1}$ & $([0.1,0.3],[0.25,0.4])$ & $([0.5,0.7],[0.6,0.7])$ & $([0.3,0.6],[0.45,0.65])$ \\
\hline $\mathrm{C}_{2}$ & $([0.3,0.6],[0.45,0.65])$ & $([0.1,0.3],[0.25,0.4])$ & $([0.5,0.7],[0.6,0.7])$ \\
\hline $\mathrm{C}_{3}$ & $([0.2,0.55],[0.3,0.55])$ & $([0.3,0.6],[0.45,0.65])$ & $([0.6,0.9],[0.75,1.0])$ \\
\hline $\mathrm{C}_{4}$ & $([0.6,0.9],[0.75,1.0])$ & $([0.3,0.6],[0.45,0.65])$ & $([0.3,0.6],[0.45,0.65])$ \\
\hline $\mathrm{C}_{5}$ & $([0.3,0.6],[0.45,0.65])$ & $([0.5,0.7],[0.6,0.7])$ & $([0.1,0.3],[0.25,0.4])$ \\
\hline $\mathrm{C}_{6}$ & $([0.5,0.7],[0.6,0.7])$ & $([0.3,0.6],[0.45,0.65])$ & $([0.6,0.9],[0.75,1.0])$ \\
\hline $\mathrm{C}_{7}$ & $([0.2,0.55],[0.3,0.55])$ & $([0.5,0.7],[0.6,0.7])$ & $([0.6,0.9],[0.75,1.0])$ \\
\hline $\mathrm{C}_{8}$ & $([0.3,0.6],[0.45,0.65])$ & $([0.6,0.9],[0.75,1.0])$ & $([0.2,0.55],[0.3,0.55])$ \\
\hline $\mathrm{C}_{9}$ & $([0.6,0.9],[0.75,1.0])$ & $([0.6,0.9],[0.75,1.0])$ & $([0.2,0.55],[0.3,0.55])$ \\
\hline $\mathrm{C}_{10}$ & $([0.6,0.9],[0.75,1.0])$ & $([0.2,0.55],[0.3,0.55])$ & $([0.5,0.7],[0.6,0.7])$ \\
\hline $\mathrm{C}_{11}$ & $([0.3,0.6],[0.45,0.65])$ & $([0.5,0.7],[0.6,0.7])$ & $([0.2,0.55],[0.3,0.55])$ \\
\hline $\mathrm{C}_{12}$ & $([0.3,0.6],[0.45,0.65])$ & $([0.1,0.3],[0.25,0.4])$ & $([0.6,0.9],[0.75,1.0])$ \\
\hline
\end{tabular}


Table 7. Shannon's Entropy weight

\begin{tabular}{|l|c|c|c|}
\hline & $\boldsymbol{E} \boldsymbol{p}_{\boldsymbol{j}}$ & $\boldsymbol{d}_{\boldsymbol{j}}$ & $\boldsymbol{w}_{\boldsymbol{j}}$ \\
\hline $\mathrm{C}_{1}$ & $([0.461,0.500],[0.502,0.498])$ & $([0.539,0.500],[0.498,0.502])$ & 0.086 \\
\hline $\mathrm{C}_{2}$ & $([0.462,0.489],[0.502,0.498])$ & $([0.538,0.511],[0.498,0.502])$ & 0.086 \\
\hline $\mathrm{C}_{3}$ & $([0.535,0.575],[0.543,0.571])$ & $([0.465,0.425],[0.457,0.429])$ & 0.084 \\
\hline $\mathrm{C}_{4}$ & $([0.576,0.584],[0.585,0.589])$ & $([0.424,0.416],[0.415,0.411])$ & 0.083 \\
\hline $\mathrm{C}_{5}$ & $([0.465,0.492],[0.504,0.501])$ & $([0.535,0.508],[0.496,0.499])$ & 0.086 \\
\hline $\mathrm{C}_{6}$ & $([0.632,0.601],[0.618,0.597])$ & $([0.368,0.399],[0.382,0.403])$ & 0.079 \\
\hline $\mathrm{C}_{7}$ & $([0.592,0.593],[0.576,0.579])$ & $([0.408,0.407],[0.424,0.421])$ & 0.081 \\
\hline $\mathrm{C}_{8}$ & $([0.537,0.575],[0.547,0.573])$ & $([0.463,0.425],[0.453,0.427])$ & 0.084 \\
\hline $\mathrm{C}_{9}$ & $([0.618,0.622],[0.606,0.623])$ & $([0.382,0.378],[0.394,0.377])$ & 0.079 \\
\hline $\mathrm{C}_{10}$ & $([0.592,0.592],[0.579,0.580])$ & $([0.408,0.408],[0.421,0.420])$ & 0.081 \\
\hline $\mathrm{C}_{11}$ & $([0.515,0.546],[0.519,0.530])$ & $([0.485,0.454],[0.481,0.470])$ & 0.084 \\
\hline $\mathrm{C}_{12}$ & $([0.478,0.518],[0.529,0.540])$ & $([0.522,0.482],[0.471,0.460])$ & 0.088 \\
\hline
\end{tabular}

By using equation (15) and (16), we compute the improved score function-based separation measures $\left(d^{+}{ }_{i}\left(A^{+}, A_{i}\right)\right.$ and $\left(d^{-}{ }_{i}\left(A^{-}, A_{i}\right)(i=1,2,3,4)\right.$, using the criteria weights in Table 7 , the results are given as;

$$
\begin{array}{ll}
\left(d^{+}{ }_{1}\left(A^{+}, A_{1}\right)=0.167,\right. & \left(d^{-}{ }_{1}\left(A^{-}, A_{1}\right)=0.123,\right. \\
\left(d^{+}{ }_{2}\left(A^{+}, A_{2}\right)=0.177,\right. & \left(d^{-}{ }_{2}\left(A^{-}, A_{2}\right)=0.115,\right. \\
\left(d^{+}{ }_{3}\left(A^{+}, A_{3}\right)=0.172,\right. & \left(d^{-}{ }_{3}\left(A^{-}, A_{3}\right)=0.119,\right. \text { and } \\
\left(d^{+}{ }_{4}\left(A^{+}, A_{4}\right)=0.170,\right. & \left(d^{-}{ }_{4}\left(A^{-}, A_{4}\right)=0.120 .\right.
\end{array}
$$

Finally, the results for the relative closeness $R_{i},(i=1,2,3,4)$ to the ideal solution which is calculated using equation (17) is given as;

$R_{1}=0.000, R_{2}=0.013, R_{3}=0.006$, and $R_{4}=0.004$, therefore the ranking orders for the four candidates are in the form (increasing order) $A_{1}<A_{4}<A_{3}<A_{2}$ ). Obviously, $A_{1}$ is the best candidate according to the proposed model.

Case 2. A hypothetical example originally presented by Ye, [21] is modified to demonstrate the computational process of the Interval-Valued Intuitionistic Fuzzy M-TOPSIS and the fuzzy Shannon entropy method algorithm.

Let us consider a decision-making problem, for the selection of a preferred Ship from a group of candidates $\left(S_{1}, S_{2}, S_{3}\right.$, and $\left.S_{4}\right)$ as a reference for a new design, where the expert have to make a decision with respect to the following criteria; Performance $\left(\mathrm{C}_{1}\right)$, Equipment $\left(\mathrm{C}_{2}\right)$ and Appearance $\left(\mathrm{C}_{3}\right)$ [34]. The criterion weight is given by $W=\{0.35,0.25,0.4\}$, the four alternative $A_{i},(i=1,2,3,4)$ is to be evaluated using the interval-valued intuitionistic fuzzy value by the experts with respect to the above criteria. The interval-valued intuitionistic fuzzy decision matrix $D_{4 \times 3}\left(x_{i j}\right)$ is given as; 


$$
\boldsymbol{D}_{4 x 3}\left(\boldsymbol{x}_{\boldsymbol{i j}}\right)=\left[\begin{array}{lcc}
([0.4,0.5],[0.3,0.4]) & ([0.4,0.6],[0.2,0.4]) & ([0.1,0.3],[0.5,0.6]) \\
([0.6,0.7],[0.2,0.3]) & ([0.6,0.7],[0.2,0.3]) & ([0.4,0.7],[0.1,0.2]) \\
([0.3,0.6],[0.3,0.4]) & ([0.5,0.6],[0.3,0.4]) & ([0.5,0.6],[0.1,0.3]) \\
([0.7,0.8],[0.1,0.2]) & ([0.6,0.7],[0.1,0.3]) & ([0.3,0.4],[0.1,0.2])
\end{array}\right]
$$

Following the implementation step of the proposed approach, the interval-valued intuitionistic fuzzy decision matrix decision matrix $D_{4 \times 3}\left(x_{i j}\right)$ above is converted to form the improved score matrix $R_{4 \times 3}\left(I_{i j}\left(a_{i j}\right)\right)$.

$$
\boldsymbol{R}_{4 \times 3}\left(\boldsymbol{I}_{i j}\left(\boldsymbol{a}_{i j}\right)\right)=\left[\begin{array}{lll}
0.535 & 0.580 & 0.235 \\
0.710 & 0.710 & 0.685 \\
0.510 & 0.600 & 0.680 \\
0.820 & 0.740 & 0.520
\end{array}\right]
$$

The weight of the criteria which is given by $W=\{0.35,0.25,0.4\}$, is applied for the computation of the improved score function-based separation measures $\left(d^{+}{ }_{i}\left(A^{+}, A_{i}\right)\right.$ and $\left(d^{-}{ }_{i}\left(A^{-}, A_{i}\right)(i=1,2,3,4)\right.$. Finally, the results for the relative closeness $R_{i},(i=1,2,3,4)$ to the ideal solution which is calculated using equation (17), the final result is shown in in Table 8 .

Table 8. Final result of the computation

\begin{tabular}{|c|c|c|c|c|}
\hline$A_{i}$ & $d^{+}{ }_{i}$ & $d^{-}{ }_{i}$ & $R_{i}$ & Ranking \\
\hline$A_{1}$ & 0.362 & 0.255 & 0.242 & 4 \\
\hline$A_{2}$ & 0.177 & 0.410 & 0.000 & 1 \\
\hline$A_{3}$ & 0.236 & 0.358 & 0.079 & 3 \\
\hline$A_{4}$ & 0.212 & 0.400 & 0.037 & 2 \\
\hline
\end{tabular}

From Table 8 , we can conclude that $A_{2}$ is the best alternative, according to the rankings order of the M-TOPSIS model.

\section{Comparison and discussion}

To further demonstrate the effectiveness of the proposed model, we have compared the results of the above hypothetical example with some similar computational approaches including the novel accuracy function-based MCDM method by Ye [21], the Linear programming method for MADM by Li [35], the entropy weights-based correlation coefficients by Ye [36], and the conventional TOPSIS model. The result of computations has been presented in Table 9.

Table 9. Comparison of results

\begin{tabular}{|c|c|c|c|c|c|c|c|c|c|c|}
\hline$A_{i}$ & $\begin{array}{c}\text { Proposed } \\
\text { method }\end{array}$ & Rank & TOPSIS & Rank & $\begin{array}{c}\text { Ye, } \\
{[21]}\end{array}$ & Rank & $\begin{array}{c}\text { Li } \\
{[37]}\end{array}$ & Rank & $\begin{array}{c}\text { Ye } \\
{[36]}\end{array}$ & $\begin{array}{c}\text { Ra } \\
\text { nk }\end{array}$ \\
\hline$A_{1}$ & 0.242 & 4 & 0.413 & 4 & 0.155 & 4 & 0.125 & 4 & 0.657 & 4 \\
\hline$A_{2}$ & 0.000 & 1 & 0.698 & 1 & 0.433 & 1 & 0.348 & 1 & 0.926 & 1 \\
\hline$A_{3}$ & 0.079 & 3 & 0.603 & 3 & 0.312 & 3 & 0.261 & 3 & 0.838 & 3 \\
\hline$A_{4}$ & 0.037 & 2 & 0.653 & 2 & 0.365 & 2 & 0.286 & 2 & 0.919 & 2 \\
\hline
\end{tabular}


With respect to the computational processes of the different approaches, the ranking results as shown in Table 9, proves to be similar. This goes to show the effectiveness of the model in ranking and handling multi-criteria problems. However, it is important to note here that there is need to apply the model to decision-making problems with more criteria and alternative.

\section{Conclusion}

In this paper, the M-TOPSIS method has been presented and extended to the intuitionistic fuzzy environment by integrating it with the fuzzy Shannon's entropy method and the improved score function of IVIFS originally proposed by Bai [16] for ranking and for the determination of preference in a multi-criteria decision-making problem within the shipping industry.

The fuzzy Shannon's entropy method have used for determining the influential criteria weight, while the improved score function is used for the calculation of the separation measures of each alternative from the positive and negative ideal solutions and for the calculation of the relative closeness coefficients in the M-TOPSIS model. The improved score function of IVIFS serves to represent the aggregated effect of positive and negative evaluations in the performance ratings of the alternatives based on interval-valued intuitionistic fuzzy set (IVIFS) data and for modeling and reflecting the hesitation of the decision-maker subjective assessment.

The proposed model has successfully been applied for ranking and for determining the most appropriate shipping partner for a shipping company located in Selangor-Malaysia, and for a hypothetical example which is based on the selection of a preferred Ship as a reference for a new design. To further demonstrate the effectiveness of the proposed model, we have compared the results of the hypothetical example with some similar computational approaches in the literature. We can conclude therefore that the new integrated model provides a better alternative method for ranking and for the determination of preference in a multi-criteria decision-making problem due to reasons.

(1) The subjective and objective weights of the criteria have been simultaneously considered using the fuzzy Shannon's entropy.

(2) The method is simple both in the concept and in the calculation procedures.

(3) It models and reflects the hesitation of the experts' subjective assessments

(4) It represents the aggregated effect of positive and negative evaluations in the performance ratings of the alternatives based on interval-valued intuitionistic fuzzy set (IVIFS) data.

Finally, in the future, we wish to recommend that the proposed model be applied to other multicriteria decision-making problems in the Shipping industry, specifically for problems with more criteria and alternatives as in the selection of Ship System Maintenance Strategy and Safety assessment for inland waterway transportation. 
Table of Acronyms

\begin{tabular}{|c|ll|}
\hline & Acronyms & \\
\hline Interval-valued intuitionistic fuzzy set & (IVIFS) & \\
\hline Interval-valued fuzzy sets & (IVVS) & \\
\hline Multi-criteria decision-making & (MCDM) & \\
\hline $\begin{array}{c}\text { Modified Technique for Order } \\
\text { Preference by Similarity to the Ideal Solution }\end{array}$ & (M-TOPSIS) & \\
\hline $\begin{array}{c}\text { Interval-Valued Intuitionistic Fuzzy } \\
\text { Modified Technique for Order Preference by } \\
\text { Similarity to the Ideal Solution }\end{array}$ & (Interval-Valued Intuitionistic Fuzzy M- & \\
\hline $\begin{array}{l}\text { Fuzzy technique for order preference } \\
\text { by similarity to ideal solution }\end{array}$ & (fuzzy-TOPSIS) & \\
\hline Intuitionistic fuzzy set & (IFS) & \\
\hline
\end{tabular}

\section{REFERENCES}

[1] D. Joshi and S. Kumar, "Intuitionistic fuzzy entropy and distance measure based TOPSIS method for multi-criteria decision making," Egypt. Informatics J., vol. 15, no. 2, pp. 97-104, 2014.

[2] H. Nguyen, S. Z. Dawal, Y. Nukman, H. Aoyama, and K. Case, "An Integrated Approach of Fuzzy Linguistic Preference Based AHP and Fuzzy COPRAS for Machine Tool Evaluation," PLoS One, vol. 10, no. 9, pp. 1-25, 2015. http://dx.doi.org/10.1371/journal.pone.0133599

[3] H. Hosseininasab and M. Dehghanbaghi, "A Fuzzy Expert System for Supporting Returned Products Strategies," Int. J. Ind. Eng. Theory, Appl. Pract., vol. 22, no. 2, 2015.

[4] L. A. Zadeh, "Fuzzy sets," Inf. Control, vol. 8, pp. 338-353, 1965. http://dx.doi.org/10.1016/S0019-9958(65)90241-X

[5] Hwang C. L. and Yoon K., Multiple Attribute Decision Making Methods and Applications. Berlin: Springer, 1981. http://dx.doi.org/10.1007/978-3-642-48318-9

[6] L. Ren, Y. Zhang, Y. Wang, and Z. Sun, "Comparative analysis of a novel M-TOPSIS method and topsis," Appl. Math. Res. eXpress, vol. 2007, pp. 1-10, 2007.

[7] K. T. Atanassov, "Intuitionistic fuzzy sets," Fuzzy Sets Syst., vol. 20, no. 1, pp. 87-96, 1986. http://dx.doi.org/10.1016/S0165-0114(86)80034-3

[8] Z. Zhang, J. Yang, Y. Ye, and Q. Zhang, "A generalized interval valued intuitionistic fuzzy sets theory," Procedia Eng., vol. 15, pp. 2037-2041, 2011. http://dx.doi.org/10.1016/j.proeng.2011.08.380

[9] G. M. Saurav Datta, Chitrasen Samantra, Siba Sankar Mahapatra, Goutam Mondal, Partha Sarathi Chakraborty, "Selection of internet assessment vendor using TOPSIS method in fuzzy environment," Int. J. Bus. Perform. Supply Chain Model., vol. 5, no. 1, pp. 1-27, 2013. http://dx.doi.org/10.1504/IJBPSCM.2013.051645

[10] H.-W. Liu and G.-J. Wang, "Multicriteria fuzzy decision-making methods based on intuitionistic fuzzy sets," Eur. J. Oper. Res., vol. 179, pp. 220-233, 2007. ttp://dx.doi.org/10.1016/j.ejor.2006.04.009

[11] Z. Xu and H. Liao, "A survey of approaches to decision making with intuitionistic fuzzy preference relations," Knowledge-Based Syst., vol. 80, pp. 131-142, 2015. http://dx.doi.org/10.1016/j.knosys.2014.12.034

[12] Z. Xu, S. Member, and H. Liao, "Intuitionistic fuzzy analytic hierarchy process," IEEE Trans. Fuzzy Syst., vol. 22, no. 4, p. 1, 2013. 
[13] D.-F. Li, "Multiattribute decision making models and methods using intuitionistic fuzzy sets," J. Comput. Syst. Sci., vol. 70, no. 1, pp. 73-85, 2005. http://dx.doi.org/10.1016/j.jcss.2004.06.002

[14] L. Lin, X. H. Yuan, and Z. Q. Xia, "Multicriteria fuzzy decision-making methods based on intuitionistic fuzzy sets," J. Comput. Syst. Sci., vol. 73, no. 1, pp. 84-88, 2007. http://dx.doi.org/10.1016/j.jcss.2006.03.004

[15] M. K. Jahromi, "Multiattribute decision making models and methods using intuitionistic fuzzy sets," Int. Math. Forum, vol. 7, no. 57, pp. 2847-2851, 2012.

[16] Z. Bai, "An Interval-Valued Intuitionistic Fuzzy TOPSIS Method Based on an Improved Score Function," Sci. World J., vol. 2013, pp. 1-9, 2013. http://dx.doi.org/10.1155/2013/879089

[17] Z. Xu, "Intuitionistic preference modeling and interactive decision making," in Studies in Fuzziness and Soft Computing, no. 2010, 2014, pp. 195-223.

[18] M. Liu and H. Ren, "A New Intuitionistic Fuzzy Entropy and Application in Multi-Attribute Decision Making," Information, vol. 5, no. 4, pp. 587-601, 2014. http://dx.doi.org/10.3390/info5040587

[19] S. M. Chen and C. H. Chiou, "A new method for multiattribute decision making based on interval-valued intuitionistic fuzzy sets, PSO techniques and evidential reasoning methodology," Proc. - Int. Conf. Mach. Learn. Cybern., vol. 1, no. 6, pp. 403-409, 2015.

[20] D.-F. Li, "Multiattribute decision making method based on generalized OWA operators with intuitionistic fuzzy sets," Expert Syst. Appl., vol. 37, no. 12, pp. 8673-8678, 2010. http://dx.doi.org/10.1016/j.eswa.2010.06.062

[21] J. Ye, "Multicriteria fuzzy decision-making method based on a novel accuracy function under interval-valued intuitionistic fuzzy environment," Expert Syst. Appl., vol. 36, no. 3, pp. 68996902, 2009. http://dx.doi.org/10.1016/j.eswa.2008.08.042

[22] T. Wang, H. Lee, and C. Wu, "A Fuzzy TOPSIS Approach with Subjective Weights and Objective Weights," in 6th WSEAS International Conference on Applied Computer Science, 2007, pp. 1-6.

[23] Ü. Şengül, M. Eren, S. Eslamian Shiraz, V. Gezder, and A. B. Şengül, "Fuzzy TOPSIS method for ranking renewable energy supply systems in Turkey," Renew. Energy, vol. 75, pp. 617625, 2015. http://dx.doi.org/10.1016/j.renene.2014.10.045

[24] R. Saad, M. Z. Ahmad, M. S. Abu, and M. S. Jusoh, "Hamming distance method with subjective and objective weights for personnel selection.," ScientificWorldJournal., vol. 2014, p. 865495, 2014. http://dx.doi.org/10.1155/2014/865495

[25] F. H. Lotfi and R. Fallahnejad, "Imprecise shannon's entropy and multi attribute decision making," Entropy, vol. 12, no. 1, pp. 53-62, 2010. http://dx.doi.org/10.3390/e12010053

[26] B. Bulgurcu, "Application of TOPSIS Technique for Financial Performance Evaluation of Technology Firms in Istanbul Stock Exchange Market," Procedia - Soc. Behav. Sci., vol. 62, pp. 1033-1040, 2012. http://dx.doi.org/10.1016/j.sbspro.2012.09.176

[27] O. Jadidi, T. Hong, and F. Firouzi, "TOPSIS and fuzzy multi-objective model integration for supplier selection problem," J. Achiev. Mater. Manufactuing Eng., vol. 31, no. 2, pp. 762-769, 2008.

[28] S. Pakpour, S. V Olishevska, S. O. Prasher, A. S. Milani, and M. R. Chénier, "DNA extraction method selection for agricultural soil using TOPSIS multiple criteria decision-making model," Am. J. Mol. Biol., vol. Published, no. October, pp. 215-228, 2013.

[29] M. D. Soufi, B. Ghobadian, G. Najafi, M. R. Sabzimaleki, and T. Yusaf, "TOPSIS multicriteria decision modeling approach for biolubricant selection for two-stroke petrol engines," Energies, vol. 8, no. 12, pp. 13960-13970, 2015. http://dx.doi.org/10.3390/en81212408

[30] C. Yang and Q. Wu, "Decision Model for Product Design Based on Fuzzy TOPSIS Method," 2008 Int. Symp. Comput. Intell. Des., pp. 342-345, 2008. http://dx.doi.org/10.1109/ISCID.2008.220 
[31] M. Ghazanfari, S. Rouhani, and M. Jafari, "A fuzzy TOPSIS model to evaluate the Business Intelligence competencies of Port Community Systems," Polish Marit. Res., vol. 21, no. 2, pp. 86-96, 2014. http://dx.doi.org/10.2478/pomr-2014-0023

[32] X. Zhu, F. Wang, C. Liang, J. Li, and X. Sun, "Quality credit evaluation based on TOPSIS: Evidence from air-conditioning market in China," Procedia Comput. Sci., vol. 9, no. 10, pp. 1256-1262, 2012. http://dx.doi.org/10.1016/j.procs.2012.04.137

[33] S. Y. Chou, V. F. Yu, A. Dewabharata, and L. Q. Dat, "A fuzzy TOPSIS approach for medical provider selection and evaluation," 2012 Int. Conf. Fuzzy Theory Its Appl. iFUZZY 2012, pp. 322-326, 2012. http://dx.doi.org/10.1109/ifuzzy.2012.6409724

[34] X. Xie, D. L. Xu, J. B. Yang, J. Wang, J. Ren, and S. Yu, "Ship selection using a multiplecriteria synthesis approach," J. Mar. Sci. Technol., vol. 13, no. 1, pp. 50-62, 2008. http://dx.doi.org/10.1007/s00773-007-0259-4

[35] D.-F. Li, "Linear programming method for MADM with interval-valued intuitionistic fuzzy sets," Expert Syst. Appl., vol. 37, no. 8, pp. 5939-5945, 2010. http://dx.doi.org/10.1016/j.eswa.2010.02.011

[36] J. Ye, "Multicriteria fuzzy decision-making method using entropy weights-based correlation coefficients of interval-valued intuitionistic fuzzy sets," Appl. Math. Model., vol. 34, no. 12, pp. 3864-3870, 2010. http://dx.doi.org/10.1016/j.apm.2010.03.025

[37] D. Li, "TOPSIS-Based Nonlinear-Programming Methodology for Multiattribute Decision Making With Interval-Valued Intuitionistic Fuzzy Sets," IEEE Trans. Fuzzy Syst., vol. 18, no. 2, pp. 299-311, 2010. http://dx.doi.org/10.1109/tfuzz.2010.2041009

$\begin{array}{lll}\text { Submitted: } & \text { 16.03.2016. } & \text { Daniel Osezua Aikhuele, danbishop_22@yahoo.co.uk } \\ & & \text { Faiz Bin Mohd Turan } \\ \text { Accepted: } & 20.07 .2016, & \text { Facility of Manufacturing Engineering Universiti Malaysia Pahang, } \\ & & \text { Pekan Malaysia, 26300 }\end{array}$

